\title{
Tachykinins Processing is Significantly Impaired in PC1 and PC2 Mutant Mouse Spinal Cord S9 Fractions
}

\author{
Mouna Saidi, Soufiane Kamali, Alberto Orduna Ruiz and Francis Beaudry*
}

Groupe de Recherche en Pharmacologie Animal du Québec (GREPAQ), Département de Biomédecine Vétérinaire, Faculté de Médecine Vétérinaire, Université de Montréal, SaintHyacinthe, Québec, Canada

*Corresponding author:

Francis Beaudry, Ph.D.

Associate Professor in Analytical Pharmacology

Département de Biomédecine Vétérinaire

Faculté de Médecine Vétérinaire

Université de Montréal

3200 Sicotte

Saint-Hyacinthe, QC

Canada J2S 2M2

Email: francis.beaudry@umontreal.ca

Keywords: Tachykinin, Substance P, Proprotein convertases, Proteolysis, Pain, Spinal cords, Mass spectrometry 


\begin{abstract}
Substance $\quad \mathrm{P}$ (SP) play a central role in nociceptive transmission and it is an anist of the Neurokinin-1 receptor located in the lamina I of the spinal cord. SP is a major proteolytic product of the protachykinin-1 primarily synthesized in neurons. Proprotein convertases (PCs) are extensively expressed in the central nervous system (CNS) and specifically cleave at C-terminal of either a pair of basic amino acids, or a single basic residue. The proteolysis control of endogenous protachykinins has a profound impact on pain perception and the role of PCs remain unclear. The objective of this study was to decipher the role of PC1 and PC2 in the proteolysis surrogate protachykinins (i.e. Tachykinin 20-68 and Tachykinin 58-78) using cellular fractions of spinal cords from wild type (WT), $\mathrm{PC}^{-/+}$and $\mathrm{PC}^{-/+}$animals and mass spectrometry. Full-length Tachykinin 20-68 and Tachykinin 58-78 was incubated for 30 minutes in $\mathrm{WT}, \mathrm{PC}^{-/+}$and $\mathrm{PC}^{-/+}$ mouse spinal cord S9 fractions and specific C-terminal peptide fragments were identified and quantified by mass spectrometry. The results clearly demonstrate that both PC1 and PC2 mediate the formation of SP and Tachykinin 58-71, an important SP precursor, with over 50\% reduction of the rate of formation in mutant PC 1 and PC2 mouse S9 spinal cord fractions. The results obtained revealed that PC1 and PC2 are involved in the C-terminal processing of protachykinin peptides and suggest a major role in the maturation of the protachykinin-1 protein.
\end{abstract}




\begin{tabular}{|c|c|}
\hline \multicolumn{2}{|c|}{ Abbreviations } \\
\hline SP & Substance P \\
\hline NKA & Neurokinin A \\
\hline NK1 & Neurokinin 1 receptor \\
\hline CPE & Endopeptidases E \\
\hline TAC1 & Tachykinin precursor 1 \\
\hline NPK & Neuropeptide K \\
\hline $\mathrm{NP} \gamma$ & Neuropeptide $\gamma$ \\
\hline $\mathrm{PCs}$ & Proprotein convertases \\
\hline Tach $_{20-68}$ & $\beta$-Preprotachykinin $20-68$ \\
\hline $\operatorname{Tach}_{58-71}$ & $\beta$-Tachykinin ${ }_{58-71}$ \\
\hline $\operatorname{Tach}_{58-70}$ & $\beta-$ Tachykinin $_{58-70}$ \\
\hline TFA & Trifluoroacetic acid \\
\hline MS & Mass spectrometry \\
\hline $\mathrm{MS} / \mathrm{MS}$ & Tandem mass spectrometry \\
\hline HPLC & High performance liquid chromatography \\
\hline IDMS & Isotope dilution mass spectrometry \\
\hline ESI & Electrospray ion source \\
\hline TIC & Total ion chromatogram \\
\hline XIC & Extracted ion chromatogram \\
\hline PAM & Peptidylglycine monooxygenase \\
\hline PHM & Peptidylglycine hydroxylase \\
\hline CNS & Central nervous system \\
\hline SRM & Selected reaction monitoring \\
\hline
\end{tabular}




\section{Introduction}

The tachykinin peptide family represents one of the most important neuropeptide family studied in mammals. Tachykinins are initially synthesized as inactive protein precursors, which require various processing enzymatic reactions to generate bioactive peptides. This typically involves endoproteolytic cleavage of precursors at the carboxyl side of specific dibasic residues (i.e. RR, RK, KR, KK), followed by the removal of basic amino acids by endopeptidases E (CPE) [1]. The tachykinin precursor 1 (Tac1) gene encodes the protachykinin-1 protein containing the sequence of four tachykinin peptides, including Substance P (SP) and Neurokinin A (NKA) [2]. Besides, the Tac1 gene also encodes other tachykinins, including neuropeptide K (NPK) and neuropeptide $\gamma(\mathrm{NP} \gamma)$ [3]. SP is reported to play a critical role in nociceptive transmission in the CNS [4, 5] and it is an agonist of the Neurokinin-1 receptor located in the lamina I of the spinal cord [6, 7]. Protachykinin-1 is primarily synthesized in neurons, and maturation occurred in large core dense vesicles present in primary afferent terminals. More specifically, a significant proportion of primary afferent neurons located in the dorsal root ganglia express high levels of SP and it is transported to both, the peripheral and central terminals. It is important to note that the expression of SP and NK1 correlates with intensity, frequency, and duration of pain [8-10].

As already suggested by previous studies [4], the protachykinin-1 protein is cleaved by the action of specific proteases into active neuropeptides by post-translational proteolytic processing during axonal transport [11]. Although, several enzymes are involved in the metabolism of the protachykinin-1 protein and tachykinin peptides, including neutral endopeptidase [12] and angiotensin converting enzyme [13], the role of proprotein convertases (PCs) remains unclear. It has been widely demonstrated that several neuropeptides are synthesized by the actions of PCs and specific endopeptidases $[11,12,14,15]$. Comprehensive studies demonstrated that PC1 and 
PC2 recognize motives composed of either a pair of basic amino acids (KR-, RR-, RK- and KK-), or a single residue ( $\mathrm{R}$ or $\mathrm{K})[16,17]$. The role of PCs in the protachykinin-1 protein C-terminal processing remains to be demonstrated, but the primary sequence of the protein suggests that PC1 and PC2 could play an important role in the release of SP. Precisely, PC1 and PC2 could be important in the synthesis of SP by cleaving at specific sites illustrated in Figure 1. The regulation of endogenous SP levels by proteolysis of precursor peptides is very important and can help to better understand the cellular and molecular mechanisms of pain.

Our main hypothesis is that $\mathrm{PC} 1$ and $\mathrm{PC} 2$ are important proteolytic enzymes involve in the processing of protachykinin-1 resulting into $\mathrm{SP}$, an important neuropeptide. Tach $_{20-68}$ and Tach $_{58-}$ 78 will be used as surrogate peptides to demonstrate specific cleavage sites shown in Figure 1. Accordingly, the main objective of this study was to decipher the role of PC1 and PC2 in the proteolysis control of $\mathrm{Tach}_{20-68}$ and $\mathrm{Tach}_{58-78}$ levels using cellular fractions of spinal cords from wild type (WT), $\mathrm{PC}^{-/+}$and $\mathrm{PC}^{-/+}$mice. Major metabolite fragments will be identified by highresolution mass spectrometry and the quantification of specific fragment peptides (i.e. Tach $_{58-71}$, Tach $_{58-70}$, SP) will be performed by HPLC-MS/MS.

\section{Materials and Methods}

\section{Chemicals and reagents}

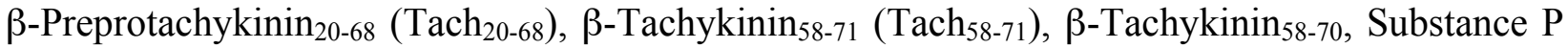
(SP) and Substance $\mathrm{P}_{3-11}\left(\mathrm{SP}_{3-11}\right)$ were purchased from Phoenix Pharmaceuticals (Belmont, CA, USA). $\beta$-Tachykinin $58-78\left(\right.$ Tach $\left._{58-78}\right)$ and deuterium labeled analogue peptides were synthesized (CanPeptide, Inc., Pointe-Claire, QC, Canada). Proteomic grade trypsin, dithiothreitol (DTT), iodoacetamide (IAA), hydrochloric acid ( $\mathrm{HCl}$ ), formic acid, water (LC-MS Optima grade), 
acetonitrile (LC-MS Optima grade), hexane, trifluoroacetic acid (TFA), sodium phosphate dibasic and sodium phosphate monobasic were purchased from Fisher Scientific (NJ, USA).

\section{Sample Preparation}

Spinal cord tissues ( $\mathrm{n}=6$ per genotypes) from male wild type $(\mathrm{C} 57 \mathrm{BL} / 6 \mathrm{~J})$, male $\mathrm{PC}^{-/+}$(product \#006327) and male $\mathrm{PC}^{-/+}$mice (product \#002963) were obtained from The Jackson Laboratory (Bar Harbor, Maine, USA) and kept frozen at $-80{ }^{\circ} \mathrm{C}$ until analysis. Heterozygote animals only were used since $\mathrm{PC}^{-/-}$and $\mathrm{PC}^{-/-}$exhibit many abnormalities and the survival rate after one week is extremely low. Animal genotyping was performed for each animal by Jackson Laboratory using a standard PCR assay. Only heterozygous and normal animals were selected for this study. All mice were 8 weeks old at time of tissues collection. The animals from all groups (WT, $\mathrm{PC}^{-1+}$ and $\mathrm{PC}^{-/+}$) were euthanized with an overdose of isoflurane followed by a transection of the cervical spine. A flush of saline was performed within the spinal canal to collect the spinal cord lumbar enlargement. Tissue samples were snap-frozen in cold hexane $\left(60{ }^{\circ} \mathrm{C}\right)$ and stored immediately at $-80{ }^{\circ} \mathrm{C}$ pending analyses. The study protocol was approved by the Institutional Animal Care and Use Committee of the Faculty of Veterinary Medicine of the University of Montreal and it was performed in accordance with the guidelines of the Canadian Council on Animal Care.

For each animal group, three spinal cords were pooled and homogenized in a $0.1 \mathrm{M}$ phosphate buffer, $\mathrm{pH} 7.4$ at a ratio of 1:5 (w:v). Samples were sonicated 20 minutes and the homogenates were centrifuged at $9,000 \mathrm{~g}$ for 20 minutes. The total amount of protein in each supernatant was determined using the standard Coomassie protein assay (Bradford). This procedure was necessary in order to assure the same amount of protein was used for each experiments. Supernatant aliquots, designated as $\mathrm{S} 9$ fractions, were kept à $-80^{\circ} \mathrm{C}$ until usage. 


\section{Metabolism study}

The incubations were performed minimally in triplicate. The incubations were performed in a microcentrifuge tube and contained $2 \mathrm{nmol} / \mathrm{mL}$ of $\mathrm{Tach}_{20-68}$ or $\mathrm{Tach}_{58-78}, 0.25 \mathrm{mg} / \mathrm{mL}$ of S9 fraction proteins diluted in $0.1 \mathrm{M}$ phosphate buffer, $\mathrm{pH}$ 7.4. Spinal cord S9 enzyme suspensions (total volume of $1 \mathrm{~mL}$ ) were preincubated with $1 \mathrm{mM} \mathrm{CaCl}_{2}$ in $0.1 \mathrm{M}$ phosphate buffer $(\mathrm{pH} 7.4$ ) at $37^{\circ} \mathrm{C}$ for 5 min prior fortification with $\mathrm{Tach}_{20-68}$ or $\mathrm{Tach}_{58-78}$. Immediately after fortification of the full-length peptide into the spinal cord $\mathrm{S} 9$ fraction suspension containing $1 \mathrm{mM} \mathrm{CaCl}$, the sampling point for $\mathrm{t}=0$ was taken, and the reaction was quenched after 30 minutes incubation. One hundred microliters of samples were taken and mixed with $100 \mu \mathrm{L}$ of an aqueous solution containing $1 \%$ TFA to stop the reaction. Samples were centrifuged at $12000 \mathrm{~g}$ for $10 \mathrm{~min}$ and $150 \mu \mathrm{L}$ of the supernatant was transferred into an injection vial and spiked with $150 \mu \mathrm{L}$ of the deuterated internal standard solution $(50 \mathrm{pmol} / \mathrm{mL}$ labeled peptides in $0.1 \%$ TFA) for mass spectrometry analysis. The rate of formation $\left(\mathrm{v}_{\mathrm{i}}\right)$ was calculated based on the concentration of each metabolite measured after 30 minutes incubation of the full-length peptides using Equation 1.

$$
v_{i}=\frac{d[P]}{d t}=\frac{[\text { peptide fragments }]}{30 \mathrm{~min}}
$$

\section{Instrumentation}

The HPLC-MS/MS system included a Thermo Accela autosampler, a Thermo Accela pump and a Thermo LTQ-XL Linear Ion Trap Mass Spectrometer (San Jose, CA, USA). Linear ion trap instruments typically have unit mass resolution throughout the mass range. The instrument was calibrated and the resolution was set at $0.5-0.7 \mathrm{Da}$ at full width at half maximum (FWHM). Further analyses were performed using a Thermo Scientific Q-Exactive Orbitrap Mass 
Spectrometer (San Jose, CA, USA) interfaced with a Thermo Scientific UltiMate 3000 Rapid Separation UHPLC system using a pneumatic assisted heated electrospray ion source.

Data were acquired and analyzed with Xcalibur (San Jose, CA, USA), and regression analyses were performed with PRISM (version 6.0f) GraphPad software (La Jolla, CA, USA) using nonlinear curve-fitting module with an estimation of the goodness of fit. The calibration lines were constructed from the peak-area ratios of targeted neuropeptides and corresponding deuterated labeled peptides used as internal standards.

\section{Peptide fragments identification}

The identification of $\mathrm{Tach}_{20-68}$ and $\mathrm{Tach}_{58-78} \mathrm{C}$-terminal processing fragments were performed using a hybrid Quadrupole-Orbitrap MS instrument (i.e. Q-Exactive Orbitrap Mass Spectrometer). MS detection was performed in positive ion mode and operating in scan mode at high-resolution, and accurate-mass (HRAM). Nitrogen was used for sheath and auxiliary gases and they were set at 10 and 5 arbitrary units. The heated ESI probe was set to $4000 \mathrm{~V}$ and the ion transfer tube temperature was set to $300^{\circ} \mathrm{C}$. The scan range was set to $\mathrm{m} / \mathrm{z} 200-2000$. Data was acquired at a resolving power of $140,000(\mathrm{FWHM})$, resulting to a scanning rate of $\approx 700 \mathrm{msec} / \mathrm{scan}$ when using automatic gain control target of $3.0 \times 10^{6}$ and maximum ion injection time of $200 \mathrm{msec}$. Product ion spectra were acquired a resolving power of 17,500 (FWHM), using automatic gain control target of $1.0 \times 10^{6}$ and maximum ion injection time of $100 \mathrm{msec}$. The collision energy set to 25 and the isolation window was set to $1.5 \mathrm{Da}$. Instrument calibration was performed prior all analysis and mass accuracy was notably below $1 \mathrm{ppm}$ using Thermo Pierce calibration solution and automated instrument protocol. All possible C-terminal processing metabolites were simulated in silico using mMass [25] to generate survey accurate masses. 


\section{Protein extraction from S9 fraction and PC1/PC2 MS analysis}

Fifty $\mu \mathrm{L}$ (i.e. precise volume varied to obtain exactly $0.5 \mathrm{mg}$ of proteins) of the $\mathrm{S} 9$ suspension was transferred to a microcentrifuge tube. The proteins were denatured by heating at $120^{\circ} \mathrm{C}$ for 10 min using heated reaction block. The solution was allowed to cool down 15 minutes and proteins were reduced with $20 \mathrm{mM}$ DTT and the reaction was performed at $60{ }^{\circ} \mathrm{C}$ for 60 minutes. Then proteins were alkylated with $40 \mathrm{mM}$ IAA and the reaction was performed at room temperature for $30 \mathrm{~min}$. Two $\mu \mathrm{g}$ of proteomic-grade trypsin was added and the reaction was performed at $40^{\circ} \mathrm{C}$ for $24 \mathrm{~h}$. The protein digestion was quenched by adding $50 \mu \mathrm{L}$ of a $1 \%$ TFA solution. Samples were centrifuged at $12,000 \mathrm{~g}$ for $10 \mathrm{~min}$ and $75 \mu \mathrm{L}$ of the supernatants were transferred into injection vials for analysis. The HPLC system was a Thermo Scientific UltiMate 3000 Rapid Separation UHPLC system. The chromatography was achieved using a gradient mobile phase along with a microbore column Thermo Biobasic C8 $100 \times 1 \mathrm{~mm}$, with a particle size of $5 \mu \mathrm{m}$. The initial mobile phase condition consisted of acetonitrile and water (both fortified with $0.1 \%$ of formic acid) at a ratio of 5:95. From 0 to 2 minute, the ratio was maintained at 5:95. From 2 to 92 minute, a linear gradient was applied up to a ratio of 50:50 and maintained for 2 minutes. The mobile phase composition ratio was reverted at the initial conditions and the column was allowed to re-equilibrate for 15 minutes. The flow rate was fixed at $75 \mu \mathrm{L} / \mathrm{min}$ and 2 $\mu \mathrm{L}$ of sample were injected. A Thermo Scientific Q-Exactive Orbitrap Mass Spectrometer was interfaced with a Thermo Scientific UltiMate 3000 Rapid Separation UHPLC system using a pneumatic assisted heated electrospray ion source. MS detection was performed in positive ion mode and operating in scan mode at high-resolution, and accurate-mass (HRAM). Nitrogen was used for sheath and auxiliary gases and they were set at 10 and 5 arbitrary units. The heated ESI probe was set to $4000 \mathrm{~V}$ and the ion transfer tube temperature was set to $300^{\circ} \mathrm{C}$. The scan range 
was set to $m / z 500-1200$. Data was acquired at a resolving power of 140,000 (FWHM), resulting to a scanning rate of $\approx 700 \mathrm{msec} / \mathrm{scan}$ when using automatic gain control target of $3.0 \times 10^{6}$ and maximum ion injection time of $200 \mathrm{msec}$. Product ion spectra were acquired a resolving power of 17,500 (FWHM), using automatic gain control target of $1.0 \times 10^{6}$ and maximum ion injection time of $100 \mathrm{msec}$. The collision energy set to 25 and the isolation window was set to $1.5 \mathrm{Da}$. Instrument calibration was performed prior all analysis and mass accuracy was notably below 1 ppm using Thermo Pierce calibration solution and automated instrument protocol. All analysis were performed in triplicate. PC1 (P63239) and PC2 (P21661) protein sequences were obtained from the The Universal Protein Resource (UniProt) databases. In silico protein digestions, peptide mass fingerprinting and MS/MS fragment ion fragmentation were performed using mMass [25]. Data analyses were performed using Thermo Scientific SIEVE (ver 2.1) and PINPOINT (ver 1.4) software (San Jose, CA, USA). The quantification of PC1 and PC2 in S9 fraction was performed at the MS level using a label-free approach and specific tryptic peptides $[26]$.

\section{Bioanalytical methods}

The chromatography was achieved using a gradient mobile phase along with a microbore column Thermo Biobasic C8 $100 \times 1 \mathrm{~mm}$, with a particle size of $5 \mu \mathrm{m}$. The initial mobile phase condition consisted of acetonitrile and water (both fortified with $0.1 \%$ of formic acid) at a ratio of 5:95. From 0 to $1 \mathrm{~min}$, the ratio was maintained at 5:95. From 1 to $12 \mathrm{~min}$, a linear gradient was applied up to a ratio of 45:55 and maintained for 3 min. The mobile phase composition ratio was reverted at the initial conditions and the column was allowed to re-equilibrate for $15 \mathrm{~min}$ for a total run time of $32 \mathrm{~min}$. The flow rate was fixed at $75 \mu \mathrm{L} / \mathrm{min}$ and $2 \mu \mathrm{L}$ of sample were injected using full loop mode. All targeted neuropeptides and deuterium labeled peptides eluted between 
6.2 to $9.3 \mathrm{~min}$. The mass spectrometer was coupled with the HPLC system using a pneumatically assisted electrospray ion source (ESI). The sheath gas was set to 25 units and the ESI electrode was set to $4000 \mathrm{~V}$ in positive mode. The capillary temperature was set at $300^{\circ} \mathrm{C}$ and the ion transfer tube voltage to $46 \mathrm{~V}$. All scan events were acquired with a $100 \mathrm{~ms}$ maximum injection time. An activation $\mathrm{q}=0.25$ and activation time of $30 \mathrm{~ms}$ were used for all targeted peptides. The mass spectrometer operated for quantitative analyses in full scan MS/MS and the quantification was based on specific post-processing SRM extracted ion chromatograms. Specific analysis details are presented in Table 1. A specific production ion was used to generate post acquisition SRM extracted ion chromatograms for quantification purposes. The method used an isotope dilution mass spectrometry (IDMS) strategy for the quantification of the targeted peptides. The peptide concentrations were determined using the peak area ratio of the light and heavy analog peptide. Tach ${ }_{20-68}$ and $\mathrm{Tach}_{58-78}$ quantification was performed using $\mathrm{d}_{5-} \mathrm{SP}$ as an internal standard and a calibration curve was constructed using Tach $_{20-68}$ and Tach $_{58-78}$ standards. The labeled peptides were used at a constant concentration of $50 \mathrm{pmol} / \mathrm{mL}$.

\section{Statistical analysis}

All data were analyzed using a one-way ANOVA followed by Dunnett multiple comparison test. Significance was set a priori to $\mathrm{p}<0.05$. The statistical analyses were performed using PRISM (version 6.0f). 


\section{Results and Discussion}

Analysis of $\mathrm{PC} 1$ and $\mathrm{PC} 2$ in mouse spinal cord $\mathrm{S} 9$ fractions

Peptide mass fingerprinting (PMF) is an analytical strategy used to identify and quantify proteins by assigning specific proteolytic fragment masses with in silico peptide masses generated using protein databases and specific digestion algorithms. The method involves that intact proteins are cleaved with a proteolytic enzyme (e.g. trypsin) to generate specific and predictable peptides. This method relies on the premise that every unique protein will have a distinctive set of peptides, consequently unique peptide masses can be found. Moreover, the PMF workflow is complemented by matching of MS/MS data for additional peptide sequence characterization. One important objective was to quantify $\mathrm{PC} 1$ and $\mathrm{PC} 2$ in $\mathrm{WT}, \mathrm{PC}^{-/+}$and $\mathrm{PC}^{-/+}$mouse spinal cord $\mathrm{S} 9$ fractions using high-resolution MS. The analytical strategy proposed in this is based on a targeted PMF method that specifically relies on upstream identification of specific PC1 and PC2 proteolytic peptides using in silico digestion to generate a mass list. To avoid false identification, only doubly and triply charges ions were survey. The protein analyses were performed using a hybrid Quadrupole-Orbitrap mass spectrometer operating in MS at a resolution of 140,000 (FWHM) and in MS/MS at a resolution of 17,500 (FWHM). Several PC1 and PC2 tryptic peptides were identified but the observed abundances were generally low. However, two specific proteolytic peptides for PC1 and PC2 were observed within 1 ppm of the exact mass. Specific XIC's (exact mass $\pm 5 \mathrm{ppm}$ ) of each targeted proteotypic peptides was used to perform label-free relative quantification based on observed ion abundance. As shown in Figure 2, PC1 and PC2 are significantly down-regulated in $\mathrm{PC}^{-/+}$and $\mathrm{PC}^{-/+}$mouse spinal cord $\mathrm{S} 9$ fractions respectively. Additionally, theses peptides were analyzed by MS/MS and spectra were dominated by y-type fragment ions with low abundance $\mathrm{b}$ ions, based on the Roepstorff and Fohlman nomenclature 
[18]. All collected MS/MS spectra were coherent with the amino acid sequence of each tryptic peptide.

High-resolution mass spectrometry analysis

$\mathrm{Tach}_{20-68}$ and $\mathrm{Tach}_{58-78}$ were used as surrogate peptides to foster a better understanding of the degradation of the protachykinin-1 protein containing the sequence of four tachykinin peptides, including SP. Degradation pathways of $\mathrm{Tach}_{20-68}$ and $\mathrm{Tach}_{58-78}$ were determined by incubating mouse spinal cord S9 fractions with full-length $\mathrm{Tach}_{20-68}$ and $\mathrm{Tach}_{58-78}$ for $30 \mathrm{~min}$ and then analyzed the quenched reactions using a hybrid Quadrupole-Orbitrap mass spectrometer operating in full-scan mode at high-resolution (i.e. $140000 \mathrm{FWHM}$ ), and accurate-mass (HRAM). The total ion chromatogram (TIC) following experiments with $\mathrm{Tach}_{20-68}$ and specific extracted ion chromatogram (XIC) shown in Figure 3 reveal that many expected peptide fragments were observed. Moreover, as illustrated in Table 2, mass accuracy observed were between -1.6 to 1.5 ppm for all detected peptide fragments. Interestingly, data clearly demonstrate that SP and SP metabolites are generated from full-length $\mathrm{Tach}_{20-68}$ in mouse spinal cord S9 fractions. Specifically, $\mathrm{SP}, \mathrm{SP}_{8-11}$ and $\mathrm{SP}_{1-7}$ were the most abundant peptide fragments observed. As suggested in Figure 1, C-terminal processing of $\mathrm{Tach}_{20-68}$ by $\mathrm{PC} 1$ or PC2 can lead to the formation of SP.

Figure 4 shows the total ion chromatogram (TIC) following experiments with $\mathrm{Tach}_{58-78}$ and specific extracted ion chromatogram (XIC). Again, many expected peptide fragments were observed, particularly C-terminal fragments. A list of the most abundant peptide fragments was shown in Table 2. The observed mass accuracy observed was between $-1.2-2.2 \mathrm{ppm}$ for all detected peptide fragments. C-terminal processing of Tach $_{58-78}$ in mouse spinal cord S9 fractions 
lead to the formation of $\mathrm{Tach}_{58-71}$, an important precursor of SP. It is well know that $\mathrm{Tach}_{58-71}$ will be cleave by endopeptidases E (CPE) and form Tach $_{58-70}$ and Tach $_{58-69}$ and then process by peptidylglycine monooxygenase (PAM) or peptidylglycine hydroxylase (PHM) to form SP. These results are very interesting since as suggested in Figure 1, C-terminal processing of Tach $_{58-}$ 78 by PC1 or PC2 can lead to the formation of Tach ${ }_{58-71}$ a precursor of SP. Please note that all MS/MS spectra acquired in high-resolution were compatible with the amino acid sequence of the peptide fragments.

\section{Quantitative analysis and Isotopic Dilution Method}

Full-scan and product ion mass spectra for all peptides and internal standards were obtained in positive ion mode. The full-scan electrospray mass spectrum of targeted peptides displayed the formation of characteristic pseudo molecular ions $[\mathrm{M}+\mathrm{nH}]^{\mathrm{n}+}$ and the fragment ions observed in MS/MS spectra were annotated based on the Roepstorff and Fohlman nomenclature [18]. Details on MS parameters and SRM transitions are reported in Table 3. Full-scan and product ion mass spectra are necessary to identify and characterize each neuropeptide. The full-scan electrospray mass spectra of targeted neuropeptides showed a base peak pseudo molecular ions at m/z 994.6 $(6+)$ for $\operatorname{Tach}_{20-68}, 602.5(+4)$ for $\operatorname{Tach}_{58-78}, 564.0(+3)$ for $\operatorname{Tach}_{58-71}, 512.0(+3)$ for $\operatorname{Tach}_{58-70}$ and $674.5(+2)$ for SP. Corresponding labeled peptides show compatible pseudo molecular ion profiles. All precursor ion masses are listed for each unlabeled and labeled peptide in Table 3. Figure 4 presents product ion spectra (MS/MS) for targeted tachykinin peptides obtained and typical b and y positive ion fragments were observed. The observed collision-induced dissociation spectra were all compatible with the peptide sequences. Additionally, we selected and optimized the most abundant and specific product ion for each peptide to generate post acquisition SRM extracted ion chromatograms in order to achieve the best sensitivity, selectivity 
and reproducibility. Furthermore, selected SRM transitions were monitored for mouse spinal cord S9 fractions and compared with reference materials. The overlay SRM extracted ion chromatograms display in Figure 5 demonstrate a suitable concordance between peptide reference standards and peptides observed in spinal cord S9 fractions following the degradation of full-length tachykinin peptides. Due to the important dilution factor of spinal cord S9 fraction used during this study, the endogenous levels were below the limit of quantification. The heavylabel versions of $\mathrm{Tach}_{58-71}, \mathrm{Tach}_{58-70}$ and SP were spiked in spinal cord S9 fractions to quantify specific N-terminal and C-Terminal $\mathrm{Tach}_{20-68}$ and $\mathrm{Tach}_{58-78}$ metabolite fragments. After optimization, the concentration of spiked labeled peptides, it was determined that a final concentration of $50 \mathrm{pmol} / \mathrm{mL}$ would lead to adequate measurements of each targeted peptide using SRM transitions. All labeled peptides are clearly distinguishable from unlabeled version by mass spectrometry, and the ratio of the unlabeled peptides to stable isotope-labeled peptides found in mouse spinal cord S9 fraction supernatants can be used to calculate the absolute concentration of each peptide monitored. The linearity response was tested at concentration raging from 1 to $500 \mathrm{pmol} / \mathrm{mL}$ for each targeted peptide. Correlation assessments between measured peak area ratios and nominal concentrations were performed and results show excellent correlations $\left(\mathrm{R}^{2}=0.9935\right.$ to 0.9986$)$. The precision and accuracy results are shown in Table 4 for all targeted tachykinin peptides. Accordingly, the analytical method provided adequate figures of merit for targeted peptide analysis performed during this study. 
Metabolic stability of Tach $20-68$ and Tach $_{58-78}$ in mouse spinal cord S9 fractions

Tachykinins concentration in mouse spinal cord is regulated by proteolysis generating a series of peptide metabolites. Tissue S9 fractions are commonly used to study metabolism since this fraction contains the cytosol and microsomes $[19,20]$. To determine the pathways for $\operatorname{Tach}_{20-68}$ and Tach $_{58-78}$ degradation in mouse spinal cord S9 fractions, we incubated spinal cord S9 fractions with full-length $\operatorname{Tach}_{20-68}$ and $\mathrm{Tach}_{58-78}$ for $30 \mathrm{~min}$ and then analyzed the quenched reactions by HPLC-MS/MS to determine the metabolic stability and identify specific $\mathrm{N}$-terminal and C-terminal fragments produced. The Figure 6 revealed that proteolysis of $\mathrm{Tach}_{20-68}$ and Tach $_{58-78}$ is occurring in mouse spinal cord S9 fractions. The results show that $>87 \%$ of the fulllength peptides degraded in 30 minutes. Furthermore, negative control (i.e. no S9 proteins) shows no degradation after a 30 minutes incubation period for both full-length peptides. Results presented in Figure 3, 4 and 6 revealed significant Tach $_{20-68}$ and Tach $_{58-78}$ degrading activity in mouse spinal cord S9 fractions.

\section{Contribution of $\mathrm{PC} 1$ and $\mathrm{PC} 2$ in Tach $_{20-68}$ C-terminal processing}

Neuropeptides are synthesized as larger precursors that undergo endoproteolysis at specific sites. Several neuropeptide-processing enzymes were identified in mammalian cells $[1,21,22]$. Proprotein convertase family including PC1 and PC2 are known to be present in numerous neuroendocrine cells. Specifically, PC1 and PC2 cleaved at the C-terminal side of paired or single basic residue within proneuropeptides [11]. Proteines convertases processing yields neuropeptide intermediates with $\mathrm{C}$-terminal basic residues ( $\mathrm{R}$ or $\mathrm{K}$ ) that are removed by carboxypeptidase E [23]. As suggested in Figure 2, we believed that PC1 or PC2 could cleave $\operatorname{Tach}_{20-68}$ in between $\mathrm{R}^{57} \mathrm{R}^{58}$ to form SP. Full-length $\mathrm{Tach}_{20-68}$ was incubated for 30 minutes in 
$\mathrm{WT}, \mathrm{PC}^{-/+}$and $\mathrm{PC}^{-/+}$mouse spinal cord $\mathrm{S} 9$ fractions and metabolites quantified by HPLCMS/MS. The rate of formation $\left(v_{i}\right)$ was determined using Equation 1. Interestingly, as shown in Figure 7A, Tach $20-68$ cleavage between $\mathrm{R}^{57} \mathrm{R}^{58}$ to form SP occurred and the rate of formation $\left(\mathrm{v}_{\mathrm{i}}\right)$ is significantly impeded in $\mathrm{PC}^{-/+}$and $\mathrm{PC}^{-/+}$mouse spinal cord $\mathrm{S} 9$ fractions. Cleavage after the pair basic amino acid was not observed $\left(\mathrm{R}^{57} \mathrm{R}^{58} \mathrm{P}^{59}\right)$ since the arginine $(\mathrm{R})$ residue at position 58 is followed by a proline (P). These results clearly demonstrate that PCs regulate SP concentration through C-terminal processing of protachykinin-1 protein and related propeptides.

\section{Contribution of $P C 1$ and $P C 2$ in Tach $_{58-78}$ C-terminal processing}

Full-length $\mathrm{Tach}_{58-78}$ was incubated for 30 minutes in $\mathrm{WT}, \mathrm{PC}^{-/+}$and $\mathrm{PC}^{-/+}$mouse spinal cord S9 fractions and specific C-terminal peptide fragments were quantified by HPLC-MS/MS. The rate of formation $\left(\mathrm{v}_{\mathrm{i}}\right)$ was determined using Equation 1. Figure 7B distinctly demonstrate that PC1 and PC2 are involved in the proteolysis of Tach $_{58-78}$ in the spinal cord. The results demonstrate that PC2 mediate the processing of $\mathrm{Tach}_{58-78}$ to $\mathrm{Tach}_{58-71}$ cleaving immediately after

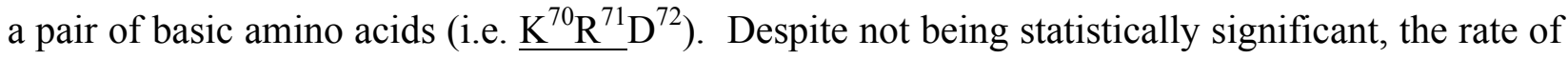
formation of $\mathrm{Tach}_{58-71}$ in $\mathrm{PC1}^{-/+}$mouse spinal cord S9 fractions was reduced. Furthermore, the rate of formation $\left(\mathrm{v}_{\mathrm{i}}\right)$ of downstream metabolites, including $\mathrm{Tach}_{58-70}$ and SP was significantly hampered in both, $\mathrm{PC}^{-/+}$and $\mathrm{PC}^{-/+}$mouse spinal cord $\mathrm{S} 9$ fractions. We believe these results shown the importance of $\mathrm{PC} 1$ and $\mathrm{PC} 2$ in the C-terminal processing of protachykinin-1 protein and related propeptides in the regulation of SP concentration in the spinal cord. 


\section{Conclusion}

The results obtained revealed that $\mathrm{PC} 1$ and $\mathrm{PC} 2$ are involved in the $\mathrm{C}$-terminal processing of protachykinin peptides and suggest a major role in the maturation of the protachykinin-1 protein. As already presented, the protachykinin-1 protein is cleaved by the action of specific proteases into active neuropeptides during axonal transport. Interestingly, depolarization of a neuron containing proneuropeptides stimulates proprotein convertases processing [24]. As a consequence, the stimulation of proprotein convertases processing will result in the liberation of higher concentration of SP into the intersynaptic space since both PC1 and PC2 are involved in the Cterminal processing of protachykinin peptides. Thus PCs could be a drug targets with the premise of partially inhibiting the release of SP. However, further study is needed since partial inhibition of PC1 or PC2 may also impact the endogenous opioid system. 


\section{Acknowledgements}

This project was funded by the National Sciences and Engineering Research Council of Canada (F. Beaudry discovery grant no. 386637-2010). The analyses were performed using analytical instruments acquired with a NSERC Research Tools and Instruments grant (F. Beaudry NSERCRTI grant No. 439748-2013). We would like to thanks Thermo Fisher Scientific for providing a generous access to a Q-Exactive Orbitrap Mass Spectrometer. M. Saidi received a Ph.D. scholarship from Mission Universitaire de Tunisie en Amérique du Nord (MUTAN). 


\section{References}

[1] Fricker LD. Neuropeptide-processing enzymes: applications for drug discovery. AAPS J. 2005;7: E449-E455.

[2] Cao YQ, Mantyh PW, Carlson EJ, Gillespie AM, Epstein CJ and Basbaum AI. Primary afferent tachykinins are required to experience moderate to intense pain. Nature (Lond.), 1998;392: 390-394.

[3] Carter MS, Krause JE. Structure expression and some regulatory mechanisms of the rat preprotachykinin gene encoding substance $\mathrm{P}$, neurokinin A, neuropeptide $\mathrm{K}$, and neuropeptide gamma, J. Neurosci. 1990;10: 2203-2214.

[4] Pailleux F, Vachon P, Lemoine J, Beaurdy F. Targeted liquid chromatography quadrupole ion trap mass spectrometry analysis of tachykinin related peptides reveals significant expression differences in a rat model of neuropathic pain. Neuropeptides. 2013;47(4):261-271.

[5] Gao Z1, Peet NP. Recent advances in neurokinin receptor antagonists. Curr Med Chem. 1999; 6(5):375-88.

[6] Teodoro FC, Tronco Júnior MF, Zampronio AR, Martini AC, Rae GA, Chichorro JG. 540 Peripheral substance $\mathrm{P}$ and neurokinin-1 receptors have a role in inflammatory 541 and neuropathic orofacial pain models. Neuropeptides. 2013;47(3):199-206.

[7] Yu XH, Zhang ET, Craig R, Shigemoto R, Ribeiro-da-Silva A. NK-1 receptor immunoreactivity in distinct morphological types of lamina I neurons of the primate spinal cord. The Journal of Neuroscience 1999;19:3545-3555.

[8] De Biasi S., A. Rustioni A. Glutamate and substance P coexist in primary afferent terminals in the superficial laminae of the spinal cord, Proc. Natl. Acad. Sci. U. S. A. 1988; 85:7820-7824.

[9] Torrealba F, Carrasco MA. A review on electron microscopy and neurotransmitter systems. Brain Res Brain Res Rev 2004;47:5-17.

[10] Slukaa KA, Baileya K, Bogusha J, Olsona R, Rickettsa A. Treatment with either high or low frequency TENS reduces the secondary hyperalgesia observed after injection of kaolin and carrageenan into the knee joint. Pain 1998;77:97-102. 
[11] Hook V, Funkelstein V, Lu L, D, Bark S, Wegrzyn, J, Hwang SR. Proteases for processing proneuropeptides into peptide neurotransmitters and hormones. Annual Review of Pharmacology and Toxicology. 2008;48:393-423.

[12] Brakch N, Rist B, Beck-Sickinger AG, Goenaga J, Wittek R, Bürger E, Brunner HR, Grouzmann E. Role of Prohormone Convertases in Pro-Neuropeptide Y Processing: Coexpression and in Vitro Kinetic Investigations, Biochemistry, 1997; 36:16309-16320.

[13] Song Y, Stål PS, Yu JG, Lorentzon R, Backman C, Forsgren S Inhibitors of endopeptidase and angiotensin-converting enzyme lead to an amplification of the morphological changes and an upregulation of the substance P system in a muscle overuse model. BMC Musculoskelet Disord. 2014;11:15-26. doi: 10.1186/1471-2474-15-126.

[14] Zheng M, Streck RD, Scott RE, Seidah NG. Pintar JE. The developmental expression in rat of proteases furin, PC1, PC2, and carboxypeptidase E: implications for early maturation of proteolytic processing capacity. Journal of Neuroscience 1994;14:4656-4673.

[15] Rouillé Y, Duguay SJ, Lund K, Furuta M, Gong Q, Lipkind G, Oliva A Jr, Chan SJ, Steiner DF. Proteolytic processing mechanism in the biosynthesis of neuroendocrine peptides: the subtilisin-like proprotein convertases, Neuroendocrinology, 1995;16:322-361.

[16] Seidah NG and Chretien M. Proprotein and prohormone convertases: a family of subtilases generating diverse bioactive polypeptides, Brain Research. 1999; 848:45-62.

[17] Seidah NG, Mayer G, Zaid A, Rousselet E, Nassoury N, Poirier S, Essalmani R, Prat A. The activation and physiological functions of the proprotein convertases. The International Journal of Biochemistry and Cell Biology. 2008;40:1111-1125.

[18] Roepstorff P and Fohlman J. Proposal for a common nomenclature for sequence ions in mass spectra of peptides. Biomedical Mass Spectrometry. 1984;11:601.

[19] Gao SM, Zhang ZP, Karnes HT. Sensitivity enhancement in liquid chromatography/atmospheric pressure ionization mass spectrometry using derivatization and mobile phase additives. J Chromatogr B. [Review]. 2005;825:98-110. 
[20] Zhanga D, Gang L, Xinxin D, Chuang L. Preclinical experimental models of drug metabolism and disposition in drug discovery and development. Acta Pharmaceutica Sinica B. 2012;549-561.

[21] Fricker LD and Devi L. Enzymes involved in the synthesis of opioid peptides, in Pharmacology of Opioid Peptides (TsengL.F.), 1995:87-107. Harwood Academic Press, Amsterdam .

[22] Berman Y, Mzhavia N, Polonskaia A, Furuta M, Steiner D F, Pintar J E and Devi. LA. Defective prodynorphin processing in mice lacking prohormone convertase PC2. Journal of Neurochemistry. 2000;75: 1763-1770.

[23] Hook V, Bark S, Gupta N, Lortie M, Weiya D Lu, Nuno B, Lydiane F, Jill W, DT O’Connor, and Pavel P. Neuropeptidomic Components Generated by Proteomic Functions in Secretory Vesicles for CellCell Communication. The AAPS Journal, 2010;12:635-645. DOI: 10.1208/s12248-010-9223-z.

[24] Yakovleva T, Bazov I, Cebers G, Marinova Z, Hara Y, Ahmed A, Vlaskovska M, Johansson B, Hochgeschwender U, Singh IN, Bruce-Keller AJ, Hurd YL, Kaneko T, Terenius L, Ekström TJ, Hauser KF, Pickel VM, Bakalkin G. Prodynorphin storage and processing in axon terminals and dendrites. FASEB J. 2006;20: 2124-2126.

[25] Strohalm M, Hassman M, Košata B, Kodíček M. mMass Data Miner: an Open Source Alternative for Mass Spectrometric Data Analysis. Rapid Commun Mass Spec 2008;22 (6): 905-908

[26] Griffin TJ, Lock CM, Li XJ, Patel A, Chervetsova I, Lee H, Wright ME, Ranish JA, Chen SS, Aebersold R, Abundance ratio-dependent proteomic analysis by mass spectrometry, Anal. Chem. 2003;75 :867-874. 
Table 1. Principal peptide fragments observed following the incubation of $\operatorname{Tach}_{20-68}$ in mouse spinal cord S9 fractions

\begin{tabular}{|c|c|c|c|c|c|}
\hline Peptide & Sequence & $\begin{array}{l}\text { Charge } \\
\text { state }(\mathrm{z})\end{array}$ & $\begin{array}{l}\text { Theoretical } \\
\text { mass }\end{array}$ & $\begin{array}{l}\text { Observed } \\
\text { Mass }\end{array}$ & $\begin{array}{l}\text { Relative } \\
\text { Error (ppm) }\end{array}$ \\
\hline Tach $_{20-68}$ & $\begin{array}{l}\text { EEIGANDDLNYWSDWYDSDQIKEELP } \\
\left.\text { EPFEHLLQRIARRPKPQQFFGLM(NH}{ }_{2}\right)\end{array}$ & 6 & 994.6548 & 994.6536 & -1.21 \\
\hline $\operatorname{Tach}_{31-68}$ & $\begin{array}{l}\text { WSDWYDSDQIKEELPEPFEHLLQRIA } \\
\text { RRPKPQQFFGLM }\left(\mathrm{NH}_{2}\right.\end{array}$ & 5 & 946.6813 & 946.6798 & -1.58 \\
\hline $\operatorname{Tach}_{35-68}$ & $\begin{array}{l}\text { YDSDQIKEELPEPFEHLLQRIARRPKP } \\
\text { QQFFGLM }\left(\mathrm{NH}_{2}\right)\end{array}$ & 5 & 831.8378 & 831.8368 & -1.20 \\
\hline SP & RPKPQQFFGLM(NH$\left.{ }_{2}\right)$ & 2 & 674.3716 & 674.3713 & 0.45 \\
\hline $\mathrm{SP}_{3-11}$ & KPQQFFGLM(NH & 2 & 547.7944 & 547.7951 & 1.28 \\
\hline $\mathrm{SP}_{8-11}$ & $\operatorname{FGLM}\left(\mathrm{NH}_{2}\right)$ & 1 & 466.2483 & 466.2490 & 1.50 \\
\hline $\mathrm{SP}_{1-7}$ & RPKPQQF & 2 & 450.7561 & 450.7566 & 1.11 \\
\hline $\operatorname{Tach}_{1-11}$ & EEIGANDDLNY & 2 & 626.7700 & 626.7705 & 0.80 \\
\hline
\end{tabular}


Table 2. Principal peptide fragments observed following the incubation of $\mathrm{Tach}_{58-78}$ in mouse spinal cord S9 fractions

\begin{tabular}{clcccc} 
Peptide & \multicolumn{1}{c}{ Sequence } & $\begin{array}{c}\text { Charge } \\
\text { state }(\mathrm{z})\end{array}$ & $\begin{array}{c}\text { Theoretical } \\
\text { mass }\end{array}$ & $\begin{array}{c}\text { Observed } \\
\text { Mass }\end{array}$ & $\begin{array}{c}\text { Relative } \\
\text { Error }(\mathrm{ppm})\end{array}$ \\
\hline Tach $_{58-78}$ & RPKPQQFFGLMGKRDADSSIE & 4 & 602.5595 & 602.5601 & -1.00 \\
& & & & & \\
Tach $_{58-71}$ & RPKPQQFFGLMGKR & 3 & 563.9838 & 563.9841 & 0.53 \\
& & & & & \\
Tach $_{58-70}$ & RPKPQQFFGLMGK & 3 & 511.9501 & 511.9507 & 1.17 \\
Tach $_{58-69}$ & RPKPQQFFGLMG & & & & \\
SP & RPKPQQFFGLM(COOH) & 2 & 703.3741 & 703.3740 & -0.14 \\
PP $_{1-9}$ & RPKPQQFFGL & 2 & 674.8634 & 674.8637 & 0.45 \\
SP $_{1-7}$ & RPKPQQF & 2 & 552.8011 & 552.8020 & 1.63 \\
\hline
\end{tabular}


Table 3. Summary of peptide quantification parameters used for HPLC-MS/MS analysis and post processing SRM

\begin{tabular}{lccccc}
\multicolumn{1}{c}{ Peptide } & $\begin{array}{c}\text { Precursor } \\
\text { ion }(\mathbf{m} / \mathbf{z})\end{array}$ & $\begin{array}{c}\text { Charge state } \\
(\mathbf{z})\end{array}$ & Product ion & $\begin{array}{c}\text { Fragment } \\
\text { ion }\end{array}$ & $\begin{array}{c}\text { Collision } \\
\text { Energy }\end{array}$ \\
\hline Tach $_{20-68}$ & 994.6 & 6 & 1137.0 & $\mathrm{y}_{37}{ }^{4+}$ & 35 \\
Tach $_{58-78}$ & 602.5 & 4 & 716.4 & $\mathrm{~b}_{19}{ }^{3+}$ & 35 \\
Tach $_{58-71}$ & 564.0 & 3 & 661.1 & $\mathrm{y}_{6}$ & 33 \\
d $_{5}$ Tach $_{58-71}$ & 565.7 & & 666.1 & & \\
Tach $_{58-70}$ & 512.0 & 3 & 652.4 & $\mathrm{y}_{6}$ & 33 \\
$\mathrm{~d}_{5}$-Tach & 513.7 & & 657.4 & & \\
$\mathrm{SP}$ & 674.5 & 2 & 600.3 & $\mathrm{~b}_{10}{ }^{2+}$ & 32 \\
$\mathrm{~d}_{5}$-SP & 677.0 & & 602.8 & & \\
\hline
\end{tabular}


Table 4. Summary of peptide quantification figure of merits obtain in fortified S9 fractions

Peptides

\begin{tabular}{lr} 
& Accuracy $(\%$ NOM \\
\hline Tach $_{20-68}$ & \\
Tach $_{58-78}$ & $95.2-110.3$ \\
Tach $_{58-71}$ & $94-5-105.6$ \\
Tach & $96.4-100.9$ \\
SP & $95.2-100.7$ \\
\hline
\end{tabular}

Spinal cords S9 fractions

Precision $(\% \mathrm{CV})$

$3.2-10.7$

$1.8-6.8$

$1.5-11.3$

$1.1-12.2$

$0.6-4.6$
$\mathrm{R}^{2}$

$\geq 0.9954$

$\geq 0.9935$

$\geq 0.9986$

$\geq 0.9954$

$\geq 0.9985$ 


\section{Figure Legends}

Figure 1. Protachykinin-1 processing by proprotein convertases (PC1 and PC2). Tachykinins have several paired and single basic amino acid cleavage sites and based on the sequence, various processing intermediates can be derived leading to SP and $\mathrm{Tach}_{58-71}$.

Figure 2. Determination of the relative abundance of PC1 and PC2 in mouse spinal cord S9 fractions using a bottom-up proteomic based analytical strategy. (A) Two specific PC1 tryptic peptides were identified and peak abundance $(\mathrm{m} / \mathrm{z} 903.0196 \pm 5 \mathrm{ppm} ; \mathrm{m} / \mathrm{z} 959.0333 \pm 5 \mathrm{ppm})$ were significantly down-regulated in $\mathrm{PC}^{-/+}$but remain unchanged in $\mathrm{PC}^{-/+}$. (B) Also, two specific PC2 tryptic peptides were identified and peak abundance $(\mathrm{m} / \mathrm{z} 922.9860 \pm 5 \mathrm{ppm} ; \mathrm{m} / \mathrm{z}$ $867.8883 \pm 5 \mathrm{ppm}$ ) were significantly down-regulated in $\mathrm{PC}^{-/+}$but remain unchanged in $\mathrm{PC}^{-/+}$.

Figure 3. Total Ion Chromatograms (TIC) and specific Extracted-ion chromatograms (XIC) for targeted tachykinin peptides following the incubation of $\mathrm{Tach}_{20-68}$ in mouse spinal cord S9 fractions. XIC's were generated using the theoretical mass value with a \pm 5 ppm extraction window. Overley XIC's of time 0 (black) and time $30 \mathrm{~min}$ (red) reveal the apparition of specific peptide fragments.

Figure 4. Total Ion Chromatograms (TIC) and specific Extracted-ion chromatograms (XIC) for targeted tachykinin peptides following the incubation of $\mathrm{Tach}_{58-78}$ in mouse spinal cord S9 fractions. XIC's were generated using the theoretical mass value with a \pm 5 ppm extraction window. Overley XIC's of time 0 (black) and time $30 \mathrm{~min}$ (red) reveal the apparition of specific peptide fragments.

Figure 5. Product ion spectra $\left(\mathrm{MS}^{2}\right)$ of $\mathrm{Tach}_{20-68}, \mathrm{Tach}_{58-78}, \mathrm{Tach}_{58-71}, \mathrm{Tach}_{58-70}$ and SP. Overlay SRM extracted ion chromatograms of a reference (black) and S9 spinal cord tissue (red).

Figure 6. Evaluation of the metabolic stability of $\mathrm{Tach}_{20-68}$ and $\mathrm{Tach}_{58-78}$ in mouse spinal cord S9 fractions. The degradation of full-length peptides occurred only with the presence of S9 proteins and demonstrates that $\mathrm{Tach}_{20-68}$ and $\mathrm{Tach}_{58-78}$ undergoes proteolytic processing in mouse spinal cord S9 fractions.

Figure 7. Assessments of $\mathrm{PC} 1$ and $\mathrm{PC} 2$ involvement in the proteolysis of $\operatorname{Tach}_{20-68}(\mathrm{~A})$ and Tach $_{58-78}$ (B). Results suggest that PC1 and PC2 are involved in the proteolytic processing of $\mathrm{Tach}_{20-68}$ and $\mathrm{Tach}_{58-78}$ leading to the formation of SP and Tach $\mathrm{T}_{5-71}$ respectively. 
Figure 1.

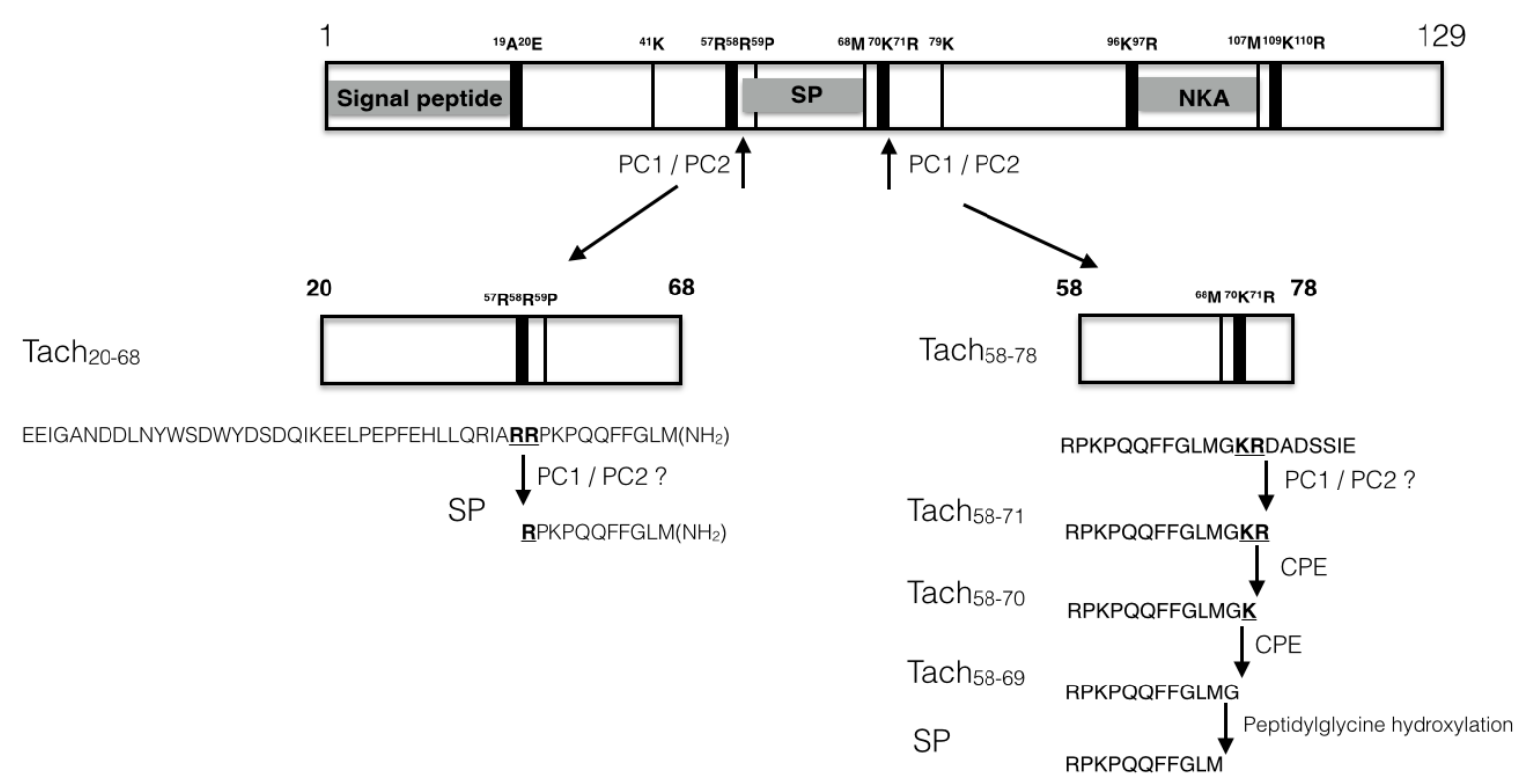




\section{Figure 2.}
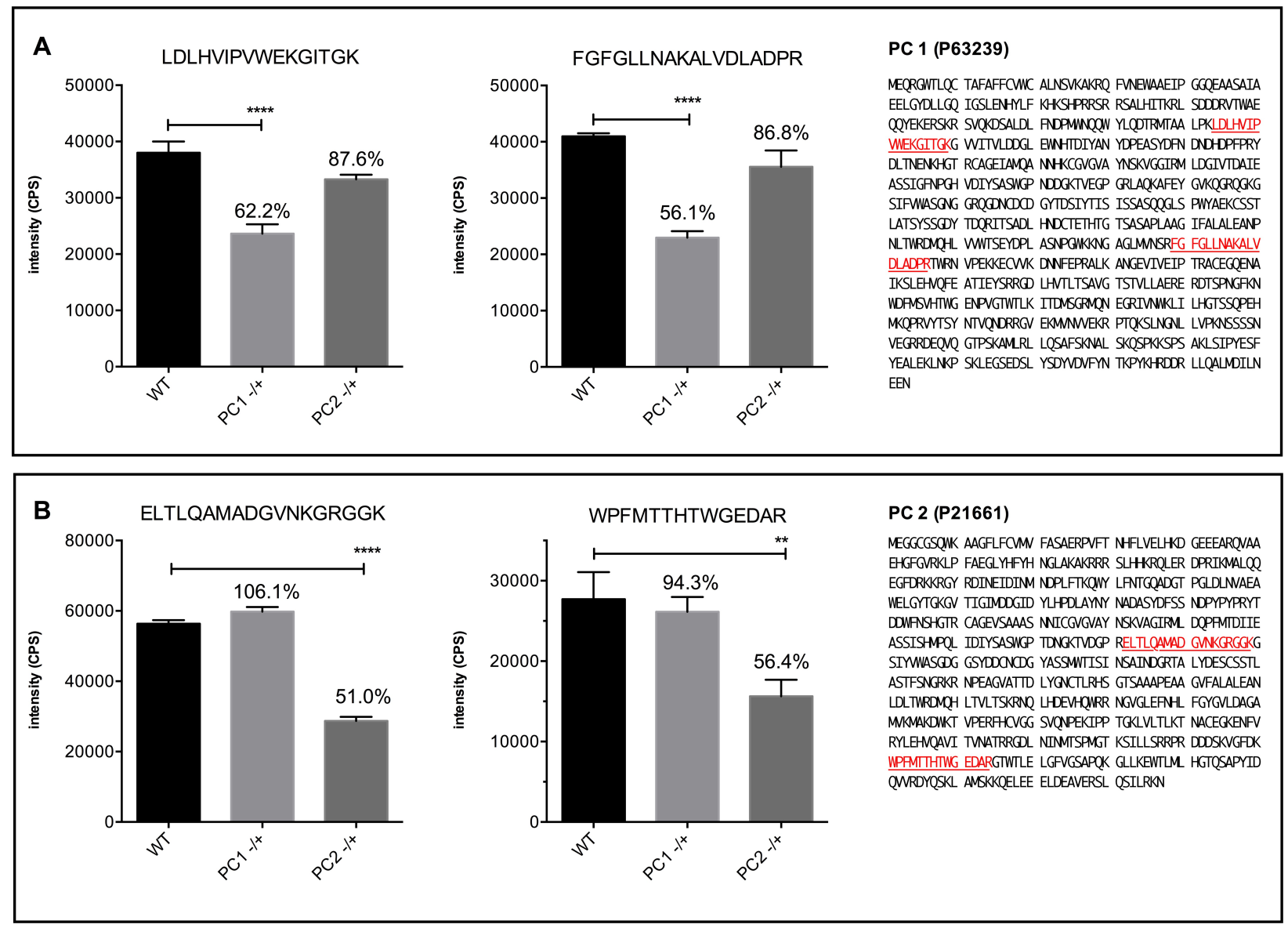

** $p<0.01$

${ }_{* * * *} p<0.0001$ 
Figure 3.
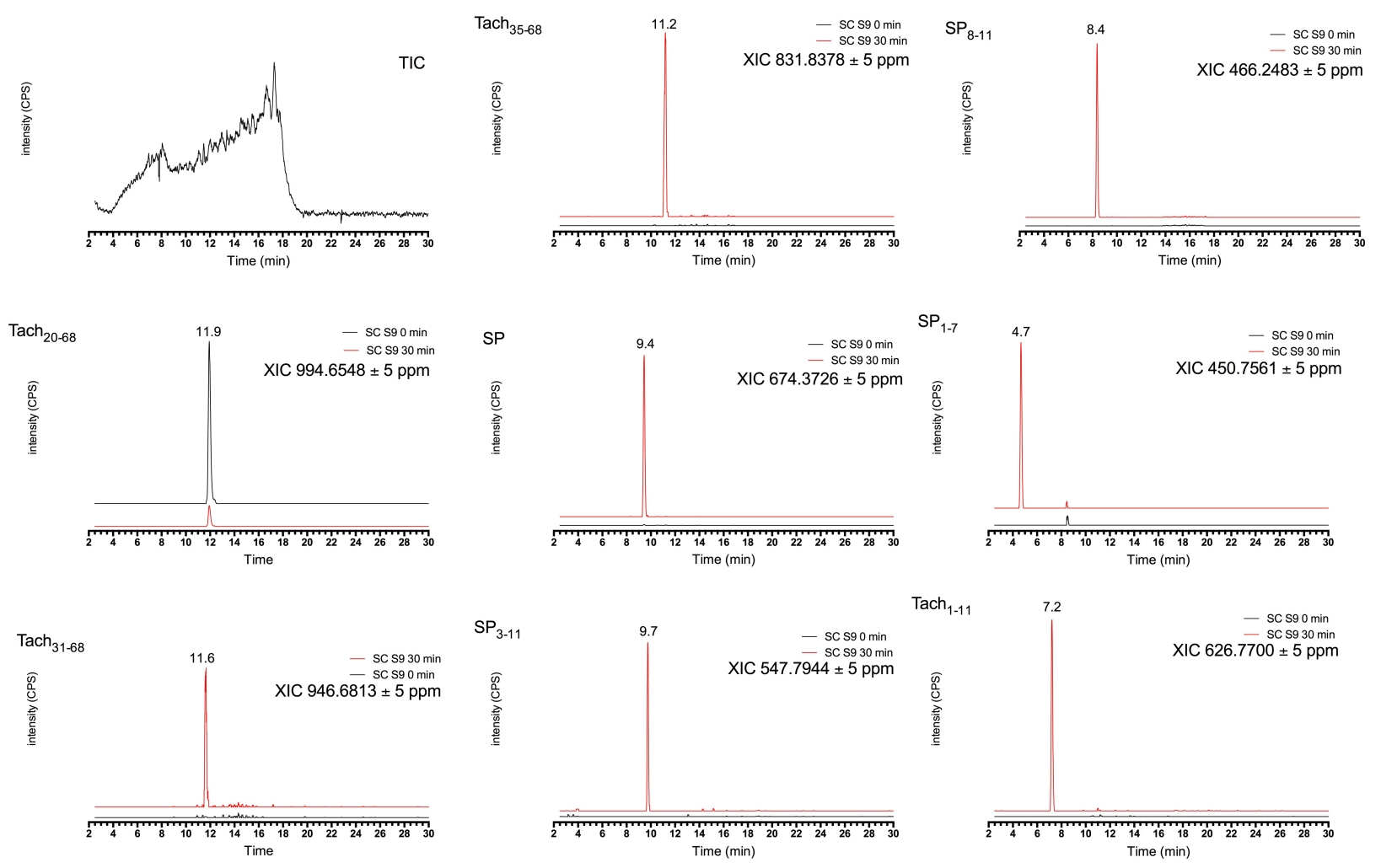
Figure 4.

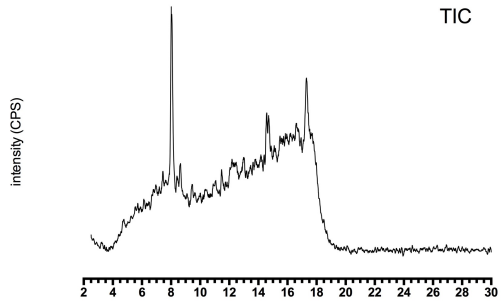

Time (min)

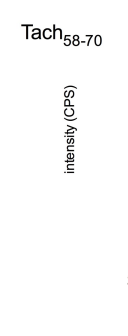

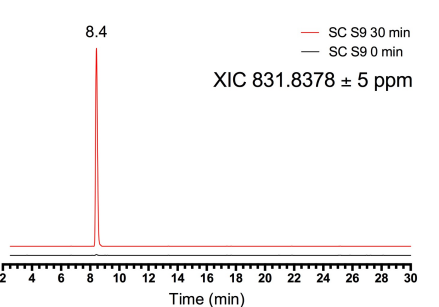
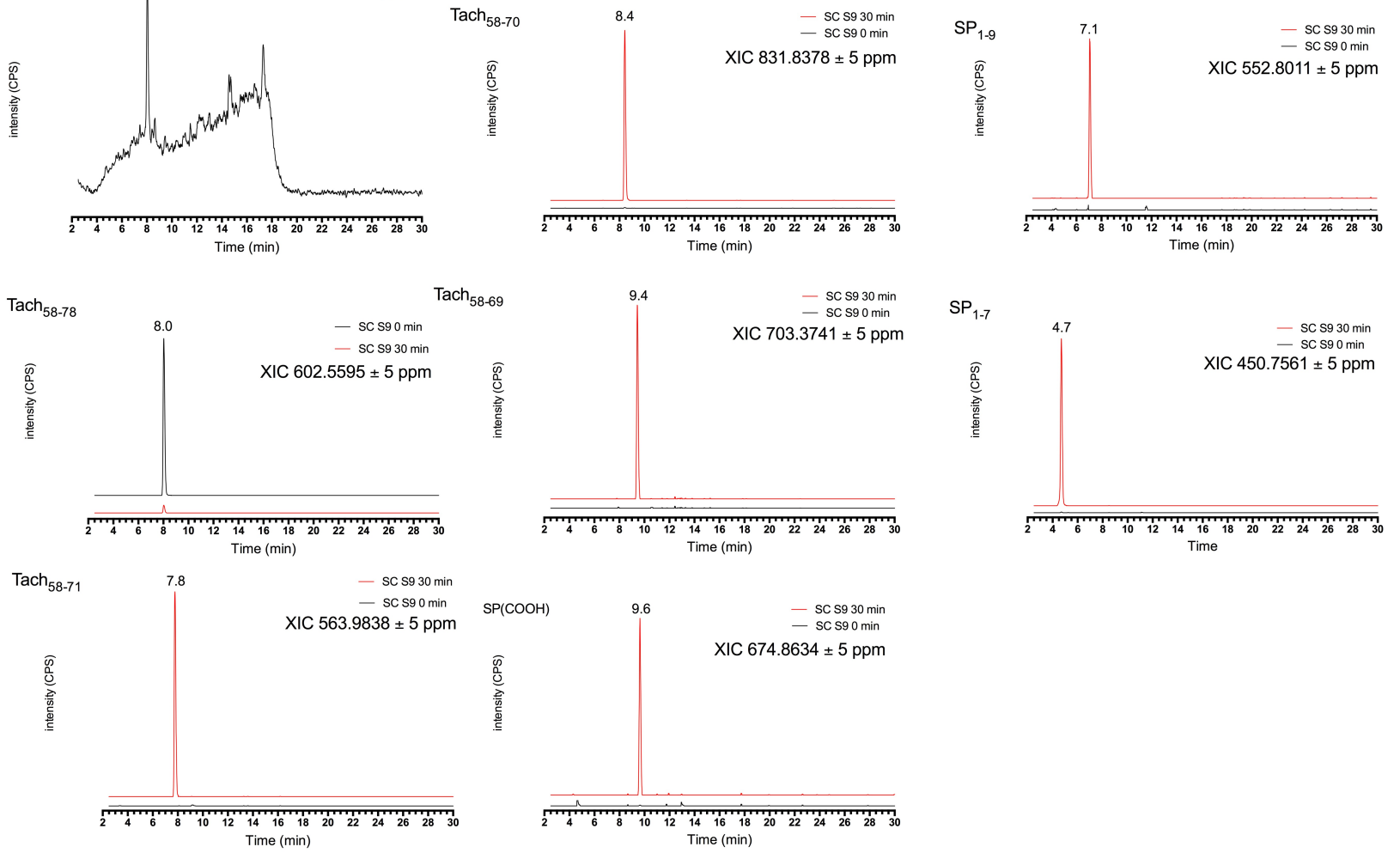


\section{Figure 5.}
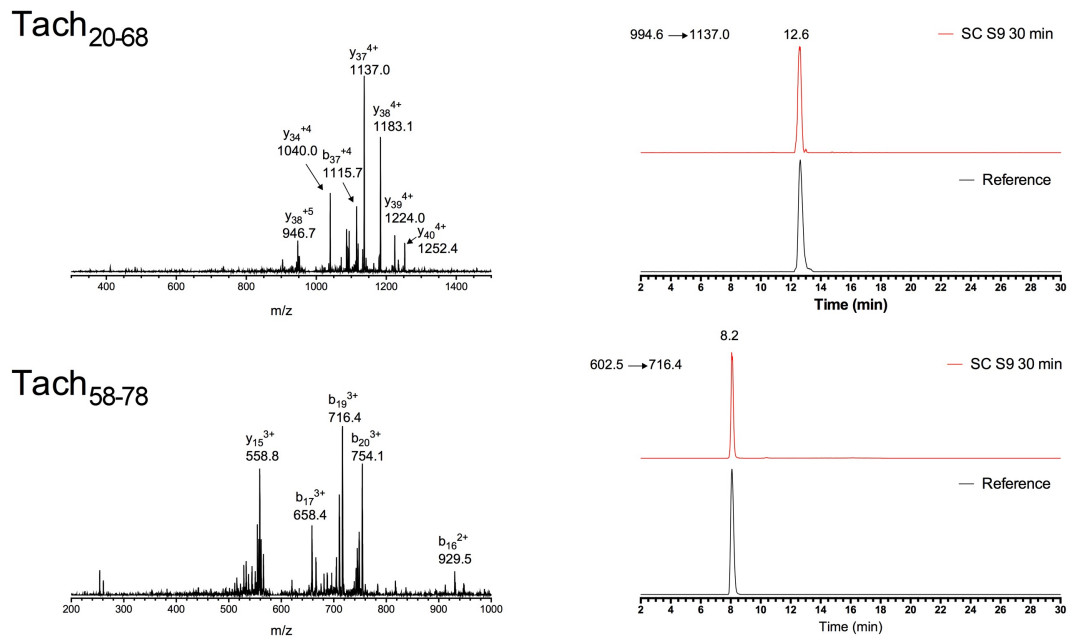

Tach $_{\text {58-71 }}$
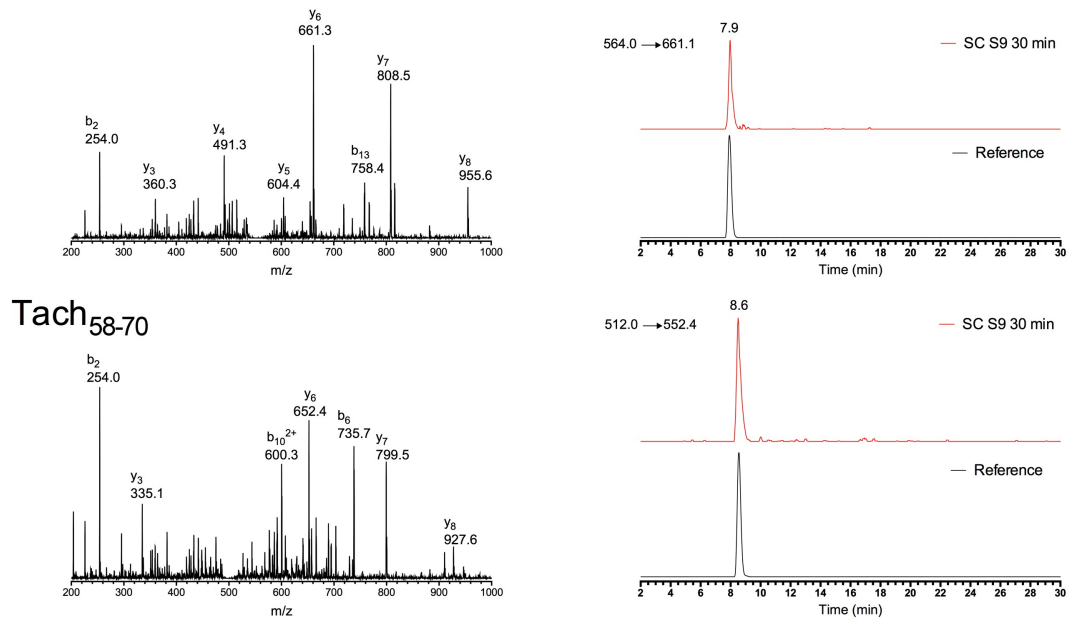

SP
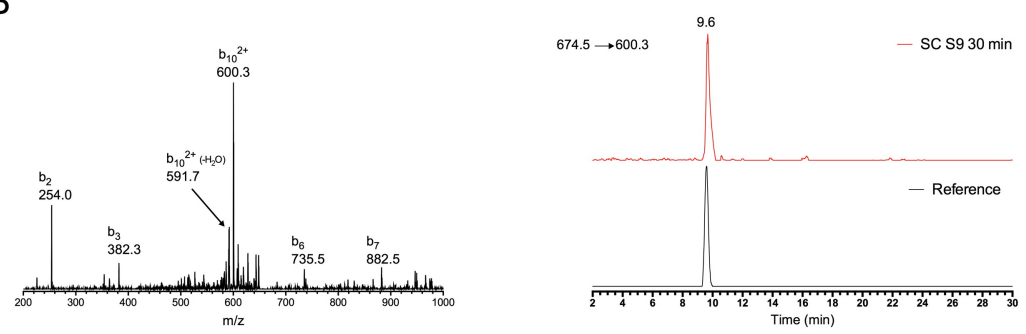
Figure 6.
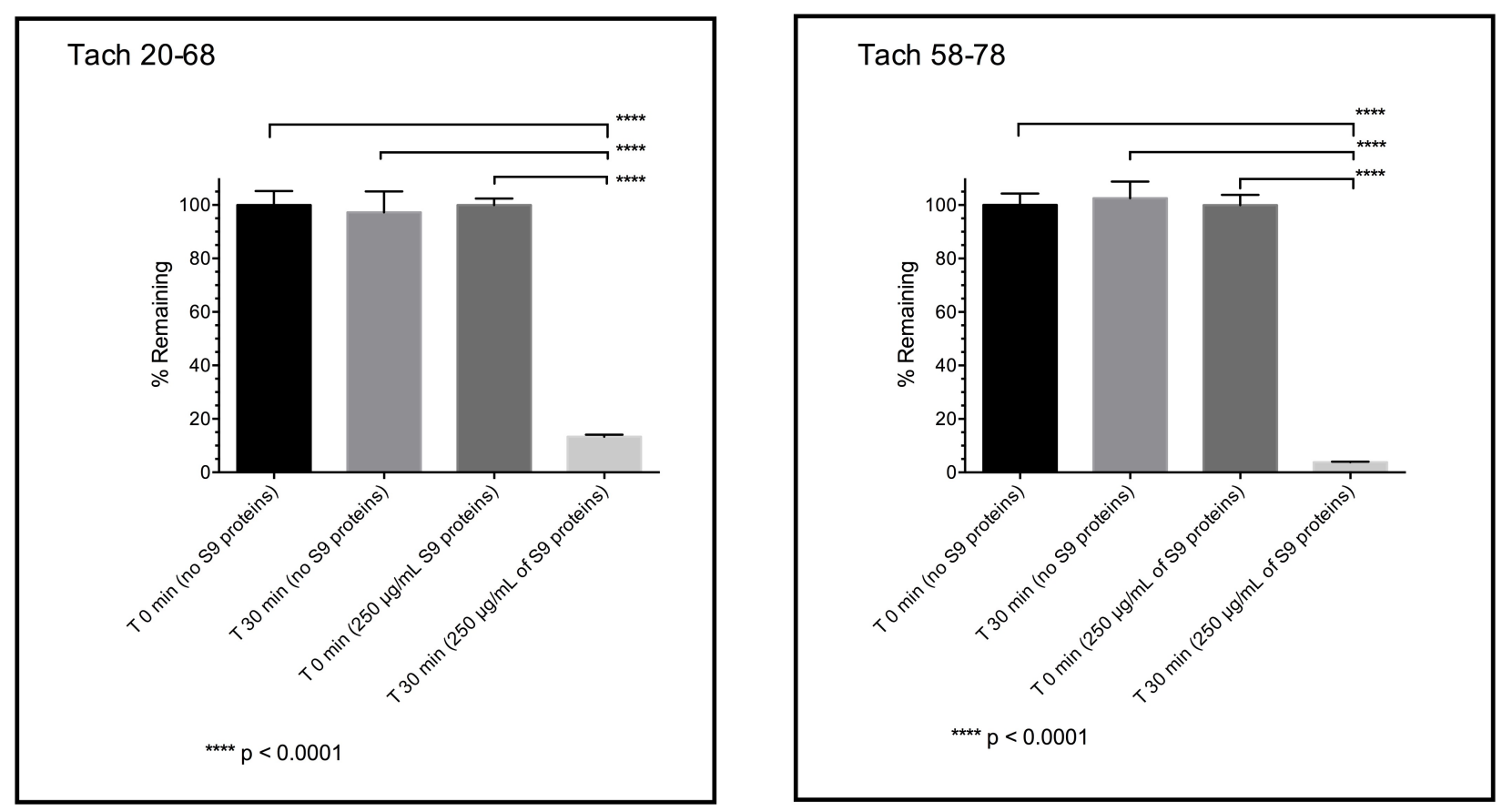
Figure 7.
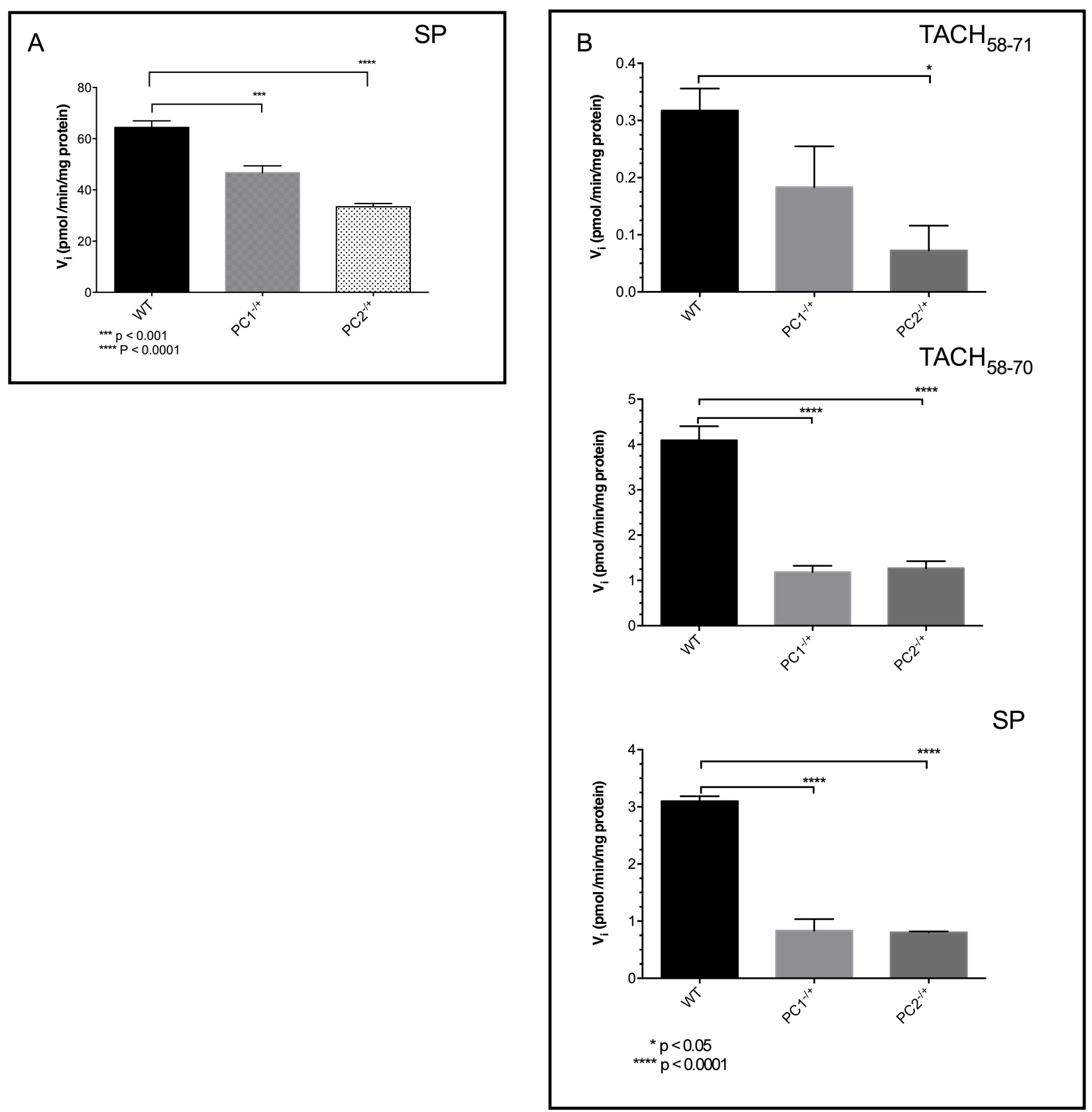